\title{
Nuevo producto de difusión del patrimonio a través de su localización cartográfica
}

\author{
El Centro de Documentación del IAPH está ultimando el diseño de un nuevo producto de difusión para \\ su portal web www.juntadeandalucia.es/cultura/iaph. Se trata de una utilidad de consulta del \\ Patrimonio Cultural de Andalucía que presenta como novedad la incorporación de una aplicación de \\ visualización cartográfica. Con ello se pretende proporcionar un nuevo servicio de acceso a la informa- \\ ción patrimonial a través de su localización y representación espacial.
}

Durante la última década, el desarrollo del Sistema de Información del Patrimonio Histórico de Andalucía (SIPHA) desde el Centro de Documentación del IAPH ha permitido generar un importante volumen de información patrimonial. Su transferencia a diferentes usuarios ha sido una de las finalidades prioritarias del SIPHA, habiéndose materializado a través de diversas actuaciones, destacando, entre otras, las contempladas en la Carta de Servicios del IAPH y los Productos de Difusión para el Portal Web. En relación con estos últimos, en la actualidad, la aplicación de los recientes desarrollos tecnológicos permite el empleo de nuevos recursos. La incorporación de herramientas para la consulta, navegación y visualización cartográfica interactiva a través de Internet ha abierto nuevas vías para la difusión de la información sobre la ubicación y distribución espacial del Patrimonio. Todo ello ha proporcionando a estos productos nuevas capacidades de comunicación, diversificando el tipo de consultas y permitiendo que el acceso a la información patrimonial sea más dinámico, intuitivo y completo para los usuarios.

\section{Las diferentes alternativas para la publicación de cartografía en Internet}

Hoy en día, Internet se ha convertido en el principal canal para la transmisión y comunicación de la información. En el caso concreto de la información geográfica, su difusión a través de la Red ha venido incrementándose en los últimos años, evolucionando desde las publicaciones iniciales de mapas estáticos, más o menos sensitivos, hasta la implantación actual de servidores cartográficos en ámbitos públicos y privados. Esta evolución está estrechamente vinculada a la consolidación de los SIG (sistemas de información geográfica) como tecnologías para la gestión y análisis de la información geográfica y a la necesidad tanto de difundir la información producida como de acceder a los datos espaciales generados. A lo largo de este proceso, la puesta en marcha de una serie de iniciativas internacionales junto con las soluciones aportadas en el ámbito de las tecnologías de la información han contribuido en gran medida a la configuración del panorama actual.

En cuanto a las primeras, la necesidad de satisfacer la demanda de información geográfica se ha puesto de relevancia a través de propuestas para la creación de las Infraestructuras de Datos Espaciales. Su objetivo fundamental es el desarrollo de los recursos necesarios para proporcionar a diferentes usuarios servicios de identificación, localización y acceso a la información espacial generada en diferentes ámbitos territoriales.

Vinculado con estas iniciativas, hay que señalar los esfuerzos realizados desde diferentes organizaciones para la definición de estánda- res que faciliten la interoperabilidad entre los diferentes servidores cartográficos. Especialmente relevante es la contribución del Open Geospatial Consortium, que desde su creación en 1994 ha venido trabajando en el desarrollo de modelos abiertos que se han concretado en una serie de especificaciones técnicas para herramientas de libre distribución, destacando especialmente los servicios de presentación de mapas, Web Map Services, y los de descarga de entidades, Web Feature Services y Web Coverage Services.

Por último, el desarrollo de nuevas soluciones tecnológicas basadas en los modelos de comunicación definidos a partir del 2003 desde el World Wide Web Consortium para los Web Services ha contribuido, en el ámbito de la difusión cartográfica, a la definición y consolidación de los Web Map Services.

Sin embargo los servidores de mapas no son la única alternativa para la publicación de cartografía en Internet. La aparición en el verano de 2005 de las aplicaciones de georrepresentación Google Maps y Google Earth ha supuesto un fenómeno impactante entre los usuarios de Internet. A ello han contribuido su capacidad para gestionar la visualización de diferentes datos geográficos, ortofotos e imágenes de satélite con cobertura global, así como la posibilidad de acceder a los mismos de forma sencilla, rápida y 


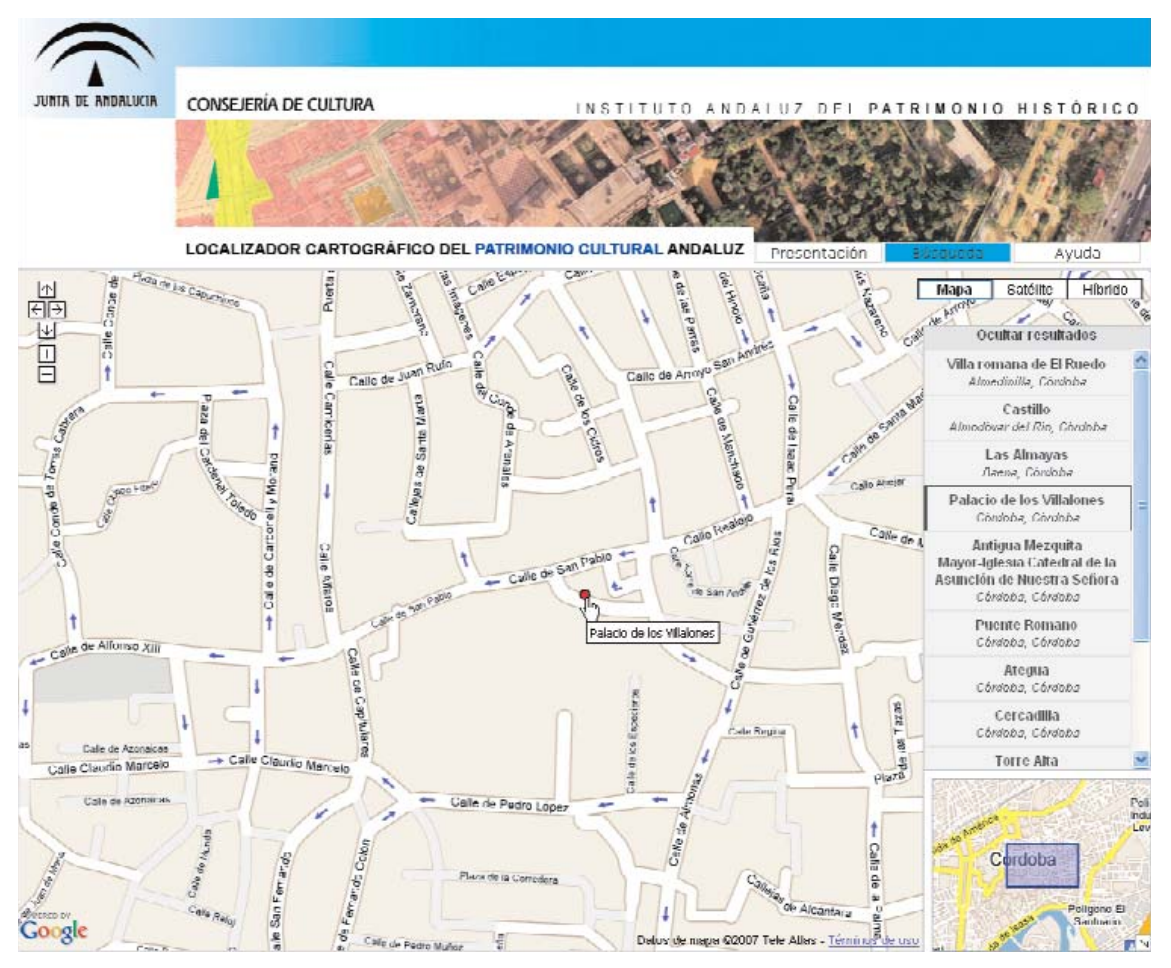

Google Maps resulta una aplicación interesante para la difusión de la información espacial del patrimonio cultural

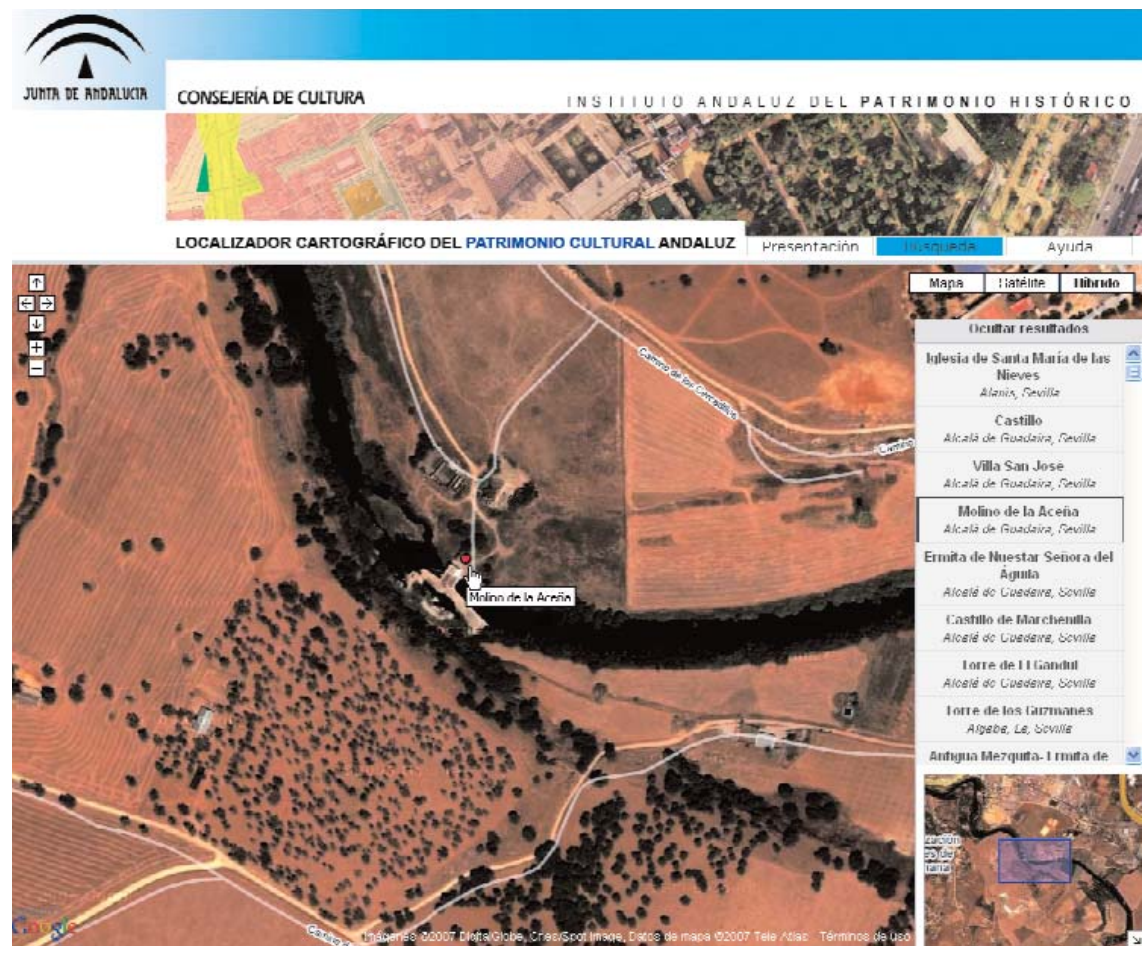


atractiva. La evolución desde entonces de este producto ha venido a consolidar su liderazgo al tiempo que ha potenciado la aparición de otros de características similares. No obstante, aún más interesante ha sido la publicación, de forma paralela a la aparición de estos productos, de una interfaz de desarrollo de fácil configuración (API) basado en el producto Google Maps. Con ella se pone a disposición de un amplio número de usuarios una herramienta que permite el diseño de aplicaciones (mashups) que combinan el uso de Google Maps con diversas fuentes de datos.

La elección de un servidor de mapas frente a la alternativa de Google Maps para el desarrollo de nuestro producto de difusión presentaba una serie de ventajas e inconvenientes. De este modo, implementar un servidor de mapas requiere una infraestructura tecnológica de gran capacidad y suficientemente optimizada para asegurar un adecuado rendimiento del servicio. Por otro lado, conlleva la necesidad de disponer de una gran cantidad de datos espaciales de referencia actualizados, así como configurar unas reglas de visualización y etiquetado de los mismos, lo que se traduce en un gran esfuerzo en su fase de diseño y elaboración. Por el contrario, esta es la gran ventaja de Google Maps que, si bien presenta el inconveniente de no contemplar, en algunos casos, de forma satisfactoria la integración multiescala de las diversas fuentes de datos, sin embargo en su conjunto resulta una aplicación de una gran comunicación visual desde el punto de vista cartográfico, especialmente para los propósitos de un producto de difusión de la información espacial del Patrimonio Cultural.

\section{El Localizador Cartográfico}

El diseño del Localizador se ha abordado con el doble objetivo de realizar un producto para la consulta de la información y localización del Patrimonio Cultural, y de forma paralela, desarrollar la infraestructura tecnológica necesaria para normalizar la salida cartográfica de otros productos del Portal Web IAPH que así lo requerían.

En este sentido, se ha realizado un diseño basado en la interconexión entre el desarrollo de una interfaz de visualización sobre la API de Google Maps y una base de datos sobre PostGreSQL. Esta última contiene las referencias sobre la identificación y localización de las entidades patrimoniales representadas, junto a un módulo PostGis específico para el almacenamiento de los datos espaciales.

\section{El localizador permite el acceso a la información patrimonial a través de su representación cartográfica, en contexto con otras entidades territoriales}

En cuanto al Localizador, se ha elaborado un producto que permite el acceso a la información de las entidades patrimoniales a través de su localización y representación cartográfica, en contexto con otras entidades territoriales. Para ello se parte de un módulo de consulta que permite la selección de registros desde las opciones contenidas en los campos básicos de identificación del Patrimonio Inmueble. Este tipo de consulta es, aunque de forma más genérica, similar a los módulos de búsqueda de la Base de Datos del Patrimonio Inmueble (BDI) u otras del Portal Web del IAPH. Sin embargo se pretende dar un paso más a corto plazo, e incorporar un nuevo tipo de consulta a partir de la realización de grandes bloques temáticos. Para ello se está realizando un trabajo espe- cífico sobre las entidades patrimoniales del SIPHA de cara a agruparlas en base a criterios temáticos históricos y culturales.

El resultado de la selección realizada en el módulo de consulta se despliega en una nueva ventana (ver imágenes p.15) cuyo contenido fundamental se concreta en un área de visualización cartográfica, en la cual se muestran las entidades patrimoniales y territoriales a una escala que permite la representación de todos los registros seleccionados. En la misma aparece una serie de controles que permiten ejecutar operaciones básicas de navegación. Integrado en este área se ha insertado un marco de referencia territorial y un listado con el resultado de la consulta, siendo posible realizar un zoom específico a cada entidad. Desde cada bien es posible acceder a su ficha de información completa mediante la conexión con los contenidos de otros servicios del portal IAPH. De este modo, se ha establecido una relación con otros productos que permite aprovechar los desarrollos ya realizados, ampliando los recursos de cada uno. Inicialmente esta relación se ha contemplado con la Base de datos de Arquitectura Contemporánea (RAAC), la $\mathrm{BDI}$ e Itinerarios Culturales.

Por último, es necesario señalar que este proyecto ha obligado a un profundo trabajo de revisión y adecuación de la información espacial de los bienes, procediendo en muchos casos a una nueva georreferenciación para adaptarla a los requerimientos de la herramienta de geovisualización. Por todo ello ha sido necesario realizar una selección inicial de las entidades patrimoniales que estarán disponibles para su consulta. Esta tarea se ha llevado a cabo teniendo en cuenta diversos criterios. Paulatinamente, y en función de diversos proyectos, se irá acrecentando el número de registros disponibles.

\section{José Manuel Díaz Iglesias}

David Villalón Torres

Carmen Pizarro Moreno

Centro de Documentación del IAPH 